\title{
Meat Prices
}

\author{
by CLIFTON B. LUTTRELL
}

Tr

HE SHARP INCREASE in meat prices during recent months reflects some reduction in the marketing of livestock and the continued acceleration in demand for meat. Red meat supplies dipped below year-earlier levels in May and remained slightly lower through June and July. ${ }^{1}$ In the absence of a sharp increase in demand, it is unlikely that this small decline in supply would cause such a major rise in meat prices as we have had.

Since December 1968 average prices for red meat, poultry, and fish have risen sharply, increasing at an annual rate of 20 per cent, while food prices and the consumer price index have increased at annual rates of 7 and 6 per cent, respectively (Table 1). Meat

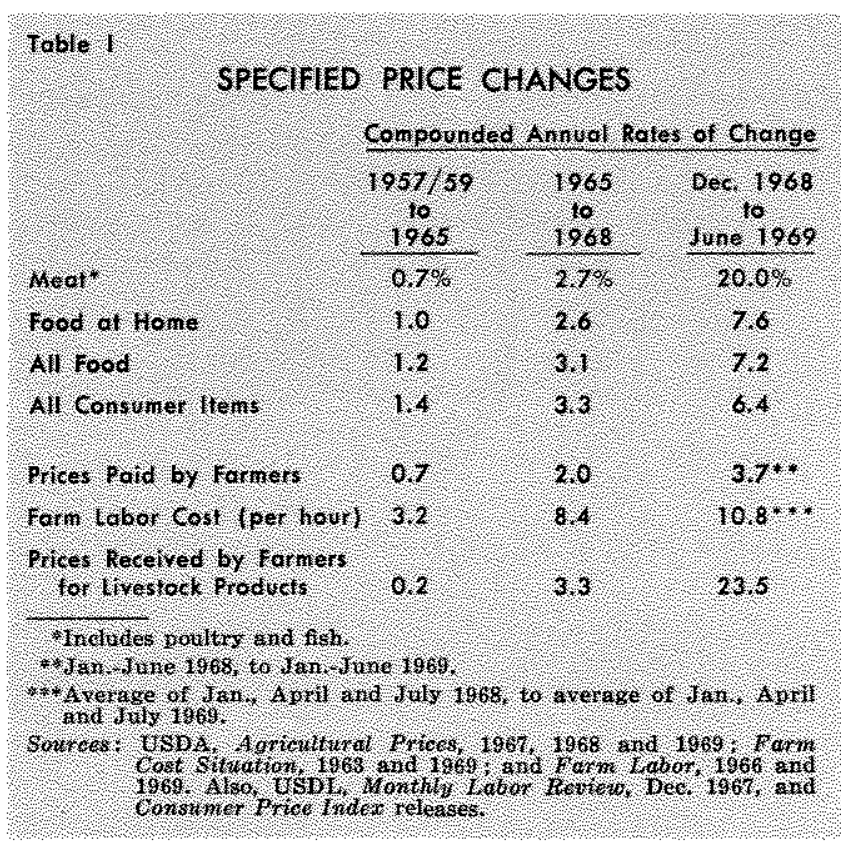

accounts for about one-fourth of all food purchases which, in turn, account for about one-fourth of personal consumption expenditures in the nation. Consequently, fluctuations in meat prices have a major impact on the consumer price index as well as on total food costs.

Excluding the impact of the slowdown in livestock marketing this year, recent short-run factors have

\footnotetext{
Thed meat supplies include beef, veal, pork, and lamb and mutton.

2Marketing year begins October 1 for corn and sorghum grain.
}

Page 24 generally been favorable to meat production. Weather conditions on farms and ranches have been normal or better. Following severe droughts, cattle herds are restocked and fewer female cattle are sent to feedlots, but no unusual restocking has been noted in recent months.

Feed grain supplies are more than adequate this year. Total feed grain supplies of 217 million tons at the beginning of the current marketing year were above levels of a year earlier and well above the 1962-66 average..$^{2}$ Carry-over stocks at the end of the current year are expected to total 48.5 million tons, somewhat above average carry-over for the past three years, but less than average for the 1962-66 period.

The current situation with respect to livestock cycles (cattle and hog cycles) is also favorable to meat production. Cattle marketings usually reach a low point during the early phase of the herd build-up, when large numbers of heifers are assigned to the breeding herd. With little emphasis on herd build-up in recent months, the cattle cycle appears favorable to cattle marketings. Cyclical factors have also been favorable to hog production this year.

Cattle cycles in this century have ranged in duration from 9 to 16 years (see chart below). Recent cycles have been shorter than earlier ones, pointing to the possibility that improved market information and the reduced age of marketed animals have had an

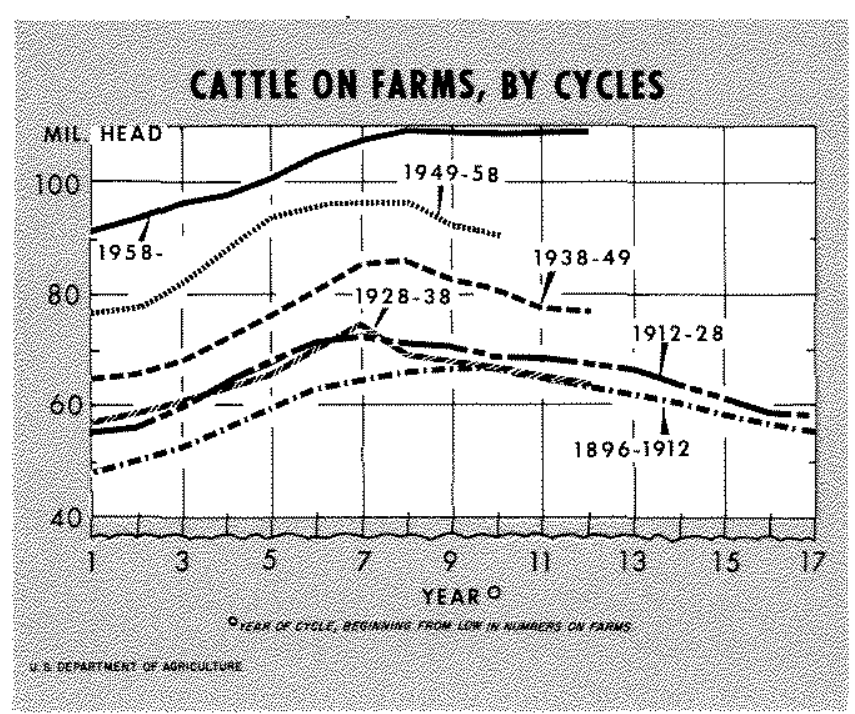


impact on adjustments by farm producers. Building cow herds is a relatively slow process compared with increasing the size of chicken tlocks or the number of breeding hogs. Market conditions can change substantially between planning and achievement of larger herds. This lag explains the cattle cycle-high prices for cattle provide incentive for farmers to increase herds; the increased herds provide a larger beef supply, causing prices to decline and, in response to lower prices, farmers begin to reduce herds. Supply and price thus move around equilibrium positions rather than along equilibrium lines

The current cattle cycle has not followed the usual pattern. Cattle numbers turned up in 1958 and typically would have reached a peak and turmed down in 1963 or 1964. In 1965, however, total cattle numbers stabilized rather than declined (see chart below). Dairy cattle declined somewhat in each of the four succeeding years, but the loss was largely offset by the increase in beef cattle. By 1964 steer prices had declined about 20 per cent from 1958 levels. Nevertheless, price prospects remained sufficiently good to provide incentive for some further beef herd enlargement. Prices of steers were somewhat higher by 1965 and have generally continued up since then. To date there is no indica tion of a major change in beef cow numbers from the modest uptrend of recent years. Thus, the cattle cycle offers no clue to the recent rise in meat prices.

Cyclical hog patterns, likewise, offer few clues to the recent upsurge in meat prices. A period of rela-

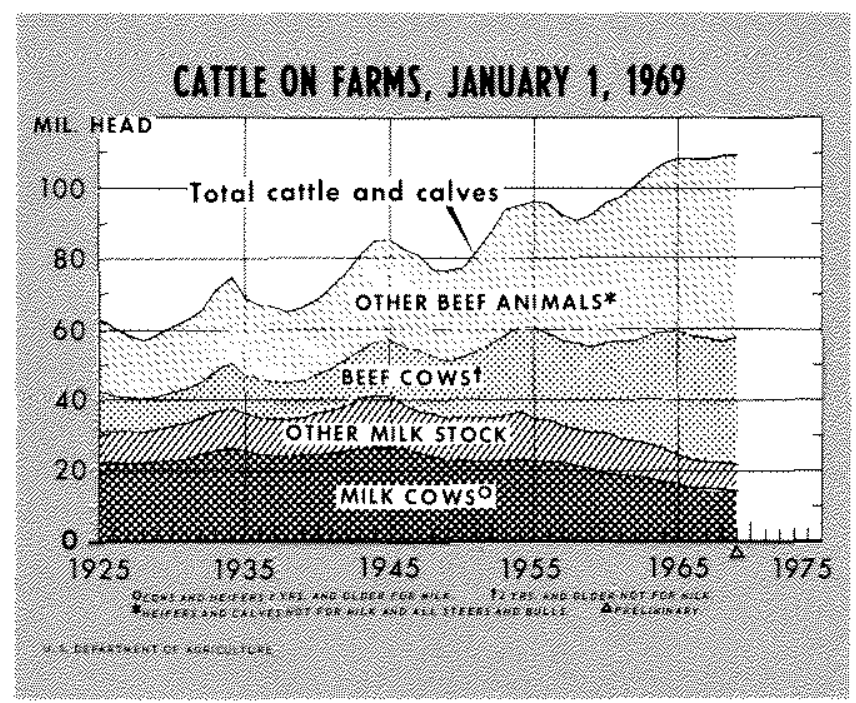

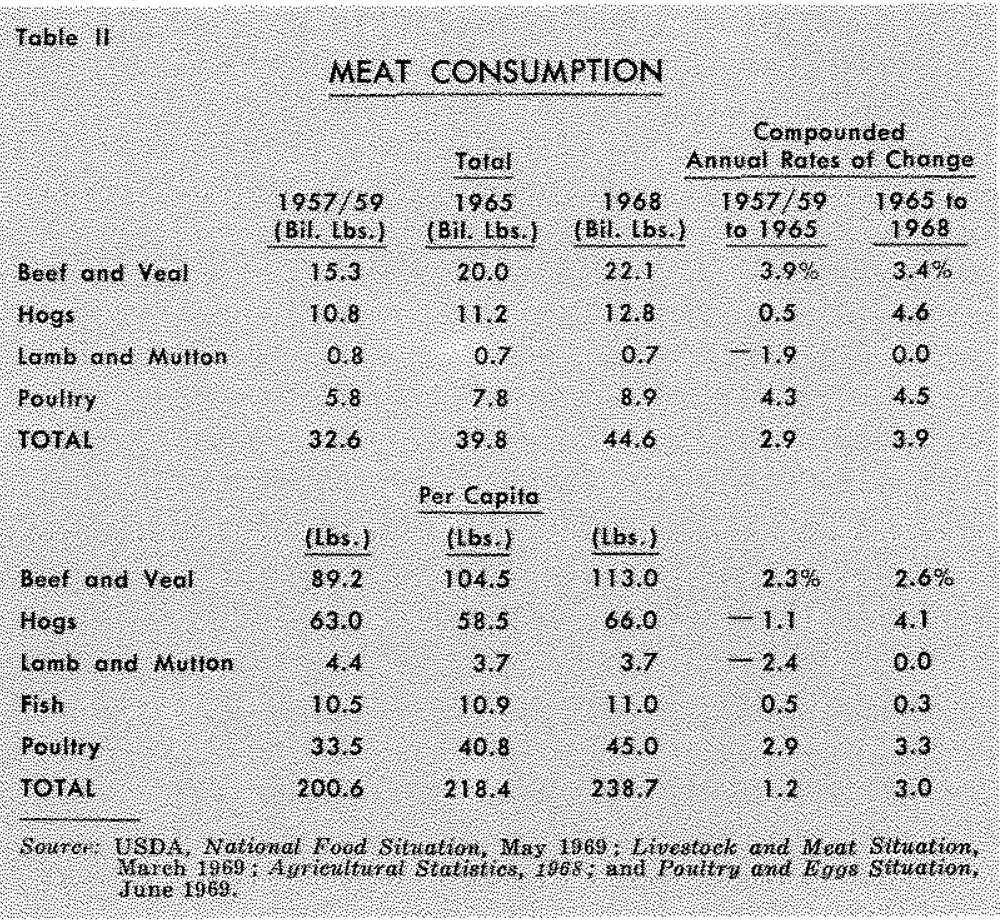

tively unfavorable corn-hog price ratios is usually followed by reduced pork production. Relatively fav. orable hog prices prevailed during most of last year; thus the cyclical factor was favorable for a gain in pork output in the first half of 1969. However, the actual gain was nominal, if any, and the March-May farrowings were down an estimated 8 per cent, well below farrowing intentions and expectations based on earlier corn-hog price relationships. Current price relationships, however, provide sufficient incentive for some increase in planned farrowings in the autumn months and perhaps larger pork production in 1970.

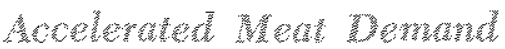

In recent years demand for meat has increased at an accelerated rate. During the $1957 / 59-65$ period consumer purchases of meat rose from 32.6 to 39.8 billion pounds, an annual rate of 2.9 per cent, and prices rose 0.7 per cent per year (Tables I and II). In the 1965-68 period consumption rose from 39.8 to 44.6 billion pounds, an annual rate of 3.9 per cent, and prices rose at an annual rate of 2.7 per cent. Despite a more rapid increase in price, pounds of meat consumed rose at a faster rate during the latter period, which indicates an accelerating increase in total demand. Meat consumption per person averaged 201 pounds in $1957-59,218$ pounds in 1965 , and 239 pounds in 1968. The annual rates of increase were 1.2 per cent from the late 1950 's to 1965 and 3 per cent since 1965. 
The accelerated increase in demand for meat in the 1965-68 period has apparently continued in 1969 . Output of red meat during the five months January through May was 1 per cent above output in the same months a year earlier. Poultry output was up about 6 per cent and meat imports were up 4 per cent during the January-April months. ${ }^{3}$ Total meat supplies were up almost 2 per cent, as poultry production and meat imports account for about 20 and 5 per cent respectively of total meat supply. Despite the increased supply, prices averaged 4.3 per cent above year-earlier levels. The fact that meat production this year rose at a somewhat slower rate than in the 1965-68 period, while prices rose faster, indicates the continued willingness of consumers to purchase larger quantities of meat at higher prices.

A shift in consumer preference to beef from other types of meat was a factor tending to increase the price of meat in the $1957 / 59-65$ period. Beef and veal constituted 47 per cent of all meat consumed in the $1957 / 59$ base period and 50 per cent in 1965 . Since 1965 the proportion of beef to total meat consumed has remained fairly stable. Beef prices have historically averaged somewhat higher than pork. During the years 1964-68 inclusive, the retail price per pound of choice beef averaged $\$ 0.83$ and veal $\$ 0.90$, while pork averaged $\$ 0.66$. These price differences reflect the higher production costs of beef and veal compared with pork.

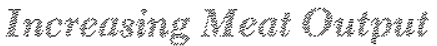

During the years $1957 / 59-65$ stable prices provided meat producers sufficient incentive to market a larger quantity of meat in successive years. Total meat and poultry production rose from 32.6 to 39.7 billion pounds, an amnual rate of 2.9 per cent (Table III). Imports accounted for a small but increasing portion of the total supply, averaging 1.0 billion pounds in $1957 / 59$ and totaling 1.3 billion pounds in 1965. During the period 1965-68 production rose from 39.7 to 44.0 billion pounds (an annual rate of 3.5 per cent), imports rose from 1.3 to 2.1 billion pounds, and farm prices for livestock products rose at the rate of 3.3 per cent.

During the years $1957 / 59-65$ each increase in demand intersected the supply curve at a relatively stable price, indicating a long-run horizontal supply curve at these

3USDA, Agriculture Outlook Digest, July 1969.

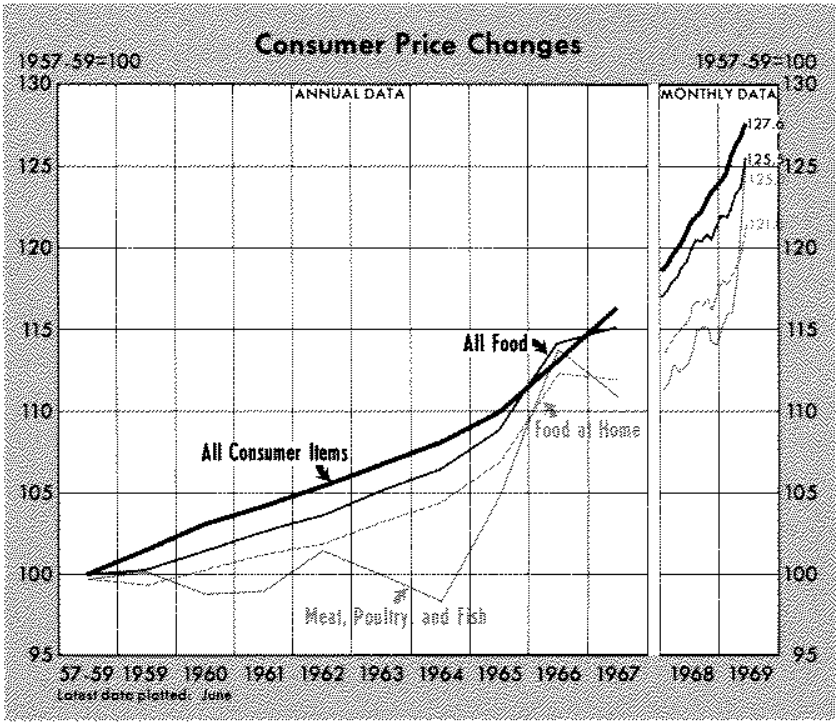

rates of increase in demand (see the Consumer Price chart above). New meat production technology offset the impact on production costs of the higher prices paid by farmers for production items. Reflecting the generally rising demand for factors of production, farm wage rates rose 3.2 per cent per year and prices paid by farmers for other production inputs rose at the rate of 0.7 per cent. Although most farm operators are also farm workers, altermative opportunities foregone for earning labor income are a cost to the operator.

After 1965 the supply curve for meat apparently changed from horizontal to upward sloping, so that successive increases in demand from 1965 to 1968 intersected the supply curve at higher average price levels. Prices rose 2.7 per cent per year in this period in contrast to almost stable prices in the earlier period. The uptrend in prices of farm inputs quickened as a result of excessive demand in resource markets. Farm wages rose at the annual rate of 8.4 per cent and prices of other farm inputs at a 2.0 per cent rate. Costs to farmers were rising at a faster rate than

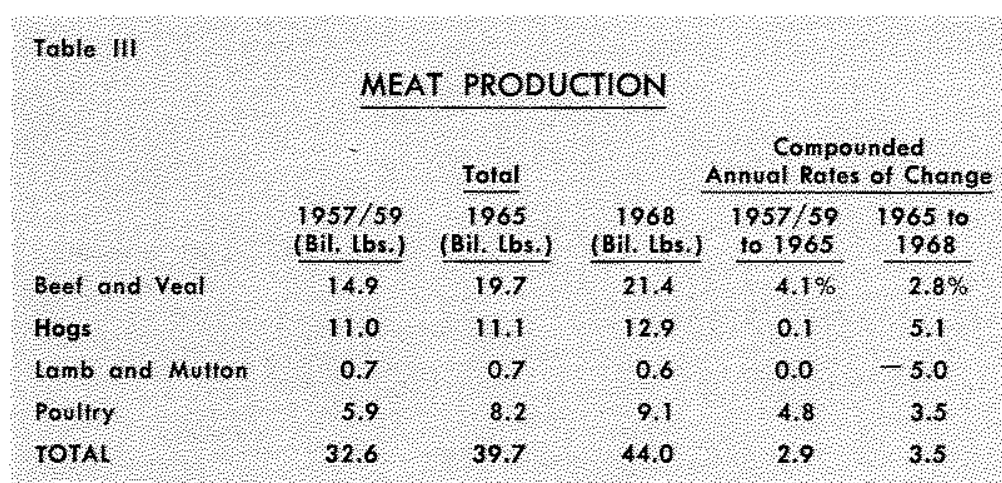

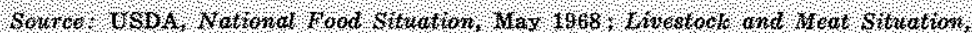

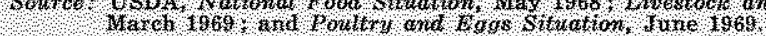


efficiency in meat production. Producers faced with a rising marginal cost curve found it profitable to produce the quantitites demanded by consumers only at higher price levels.

The slope of the supply curve may have steepened this year. As indicated earlier, meat output from January through May was up 2 per cent from the same period a year ago. Prices to producers for livestock products rose at an amnual rate of 23.5 per cent from December through June. Both beef cattle and hog prices rose at rates in excess of 50 per cent per year and chickens rose at a 30 per cent rate. Factor costs to farmers continued to increase sharply. Wage rates paid in early 1969 were 11 per cent above year ago levels, and other prices paid were 4 per cent higher.

\section{Proces}

Although underlying price-making forces in the meat industry have increased as a result of the general price inflation since December, they have risen at a much slower rate than meat animal prices. This wider spread between costs and prices received by producers indicates that short-run prices for meat animals may be above the long-run equilibrium price and that current prices provide incentive for some expansion of meat production.

As indicated earlier, part of the recent increase in meat animal prices reflects reduced supplies resulting from irregular marketing of livestock. Marketings were down somewhat in May, June, and early July from year-earlier levels. This reduction in slaughter does not reflect a decline in long-run incentive to produce. Livestock marketings are expected to be up this fall. On July 1 , cattle on feed in major feeding states were up 15 per cent from a year ago. Beef supplies are expected to be 11 per cent greater during the July-September period. Hog marketings in the second half of 1969 may be down about 2 per cent from a year ago, but an increase in summer and fall farrowings points to larger pork supplies in early 1970. Marketings of poultry throughout the rest of 1969 are expected to be larger than a year ago.

The number of basic breeding animals has not been significantly increased to date. Such increases, however, usually occur only after a time lapse.

Meat prices since 1957/59 have been maintained above equilibrium levels by government restraints on both domestic feed grain crops and imports of meat. Import restrictions provide for quotas when yearly imports of meat exceed 110 per cent of an adjusted base quota. Although these quotas have been invoked infrequently, if at all, the threat of quota restrictions has probably served to restrain meat imports.

The objective of the Feed Grain Program is to divert acreage from feed production to other uses in order to restrict supplies. About 37 million acres were diverted from feed grain use through the program this year. Farmers are provided incentive to participate in the program, both through government price supports for feed grain crops and through acreage diversion payments.

These programs, which tend to be inflexible, may have retarded the response of producers to the higher meat prices in recent years. Import controls also have had their impact primarily since 1965. Meat imports have averaged somewhat greater since 1965 than in the 1957/59-65 period. On the other hand, without the threat of quota restrictions, larger imports might have retarded the rate of increase in meat prices.

\section{Sumbarmats}

Sharply higher meat prices have been an important factor in consumer price increases since December 1968. Part of the rise in meat prices in late May and June reflects irregular marketings of livestock. Marketings from May through July were down slightly from year-earlier levels. The greater portion of cattle marketings for 1969 will apparently occur in the second half of the year. With little meat kept in storage, the gap in livestock marketed in the late spring and early summer probably resulted in livestock prices well above the longer run trend. With larger meat marketings in prospect for the second half, meat prices may be below the long-run trend.

Not all of the recent increase can be attributed to marketing irregularities or short-run cyclical factors. The long-run trend in prices for $1965-68$ probably continued this year at an accelerated rate.

Demand for meat has increased more rapidly in recent years than in the early 1960's. The high rate of increase in demand for meat has continued in 1969. While demand was increasing at a slower rate in the early 1960 's, efficiencies in production were sufficient to offset rising factor costs. Major efficiency gains have continued, but due to such demand factors as general price inflation and rising consumer preference for meat, prices have continued to increase.

Recent movements in meat prices could be considered as a catching-up process. Meat prices have increased less than all consumer items since 1957/59. 
Excessive demand for all goods and services has, however, penetrated the farm cost structure and, with a time lag, prices in agriculture must adjust to the created excesses.

Government crop production control programs and meat import quotas have contributed to higher meat prices. The crop programs have maintained feed prices above free market levels, and the quotas have inhibited imports, tending to retard meat supply increases in response to the higher prices.

When demand for all goods and services is reduced, equilibrium meat prices will probably stabilize along with other prices. Demand for meat will probably continue to rise after general price inflation subsides, but at a slower rate than in recent years. Some of the underlying meat production costs will also stabilize and efficiency growth will offset the rising costs. Part of the recent meat price gains, however, may represent a further upward adjustment in returns to resources in agriculture, bringing such returns closer to equality with returns to resources in other sectors of the economy. To the extent that higher returns are necessary to attract resources into agriculture, no major reduction in meat prices relative to other prices is in prospect. 